\title{
The Rising of Fintech - How the Tech Revolution in Financial Services Represents A Paradigm Shift
}

\author{
Johannes $\operatorname{Treu}^{1 *}$ \\ Valerie Isabel Elss ${ }^{2} *$ \\ Giovanni Buono ${ }^{3}$ \\ Pia Winkler ${ }^{4}$ \\ IU - International University of Applied Sciences, Germany ${ }^{1}$ \\ LUMSA University, Germany ${ }^{3}$ \\ FHM - University of Applied Sciences, Germany ${ }^{2 \& 4}$
}

\begin{abstract}
Finance is a field that shapes human relations not only from a purely economic point of view, but also has a strong influence on social structure, community development, prosperity, political or international interaction, which is even more relevant in a hyperglobalized world. The transformations began with the rising of the internet some decades ago and accelerated due to recent changes, such as increased computing power, the usage of financial apps etc. The scope of this paper is to present a short literature overview about the disruption brought in the finance sector by the recent technology developments. In addition to understand that technology is synonymous with innovation this paper shows examples of innovation drivers (including products and services). Finally, this paper highlights the long-term impact on social and geopolitical grounds with shifting power equilibriums, like the loosing banking monopoly of finances in favour of tech giants GAFA (Google, Amazon, Facebook, Apple) or the recent announcements of global and official cryptocurrencies, e.g. LIBRA by Facebook or CBDC (Central Banks Digital Currencies) from China government. The main findings of this paper are that FinTech has the chance to revolutionize the financial sector because it is more than just payment, new players (BigTech) could enter into the traditional banking sector and rise a new form of competition and FinTech has social impact on financial inclusion and financial literacy.
\end{abstract}

Keywords: Technology, Management, FinTech, Tech Innovation, Financial Technology

\footnotetext{
*Corresponding authors: Johannes Treu and Valerie Isabel Elss Corresponding Emails: elss@fh-mittelstand.de, johannes.treu@iu.org DOI: https://doi.org/10.37227/JIBM-2021-03-718
}

\section{Introduction}

This is a time of revolution, not the one related to political and social turmoil, rather a subtler one named "Fintech", which is a combination of the words "Finance" and "Technology" and best defined as "a new financial industry that applies technology to improve financial activities" (Schueffel, 2017) or finally as "any innovative ideas that improve financial service processes by proposing technology 
solutions according to different business situations, while the ideas could also lead to new business models or even new businesses" (Leong, 2018).

As Bill Gates said "Banking is necessary; banks are not", this phrase describes very well what is going on in the financial sector as a whole: (i) disappearing of traditional jobs, (ii) consolidation in banking industries, (iii) rapid growing of financial robots that advice how to manage and save money. Furthermore, it is possible to compare the Fintech revolution to the once occurred with the arrival of Internet in the '90, but faster. Both examples describe that a complete change will occur within the next years and affect the life of many people and the society as well. If this come true, the world will look very different from today.

The objective of this paper is to present a literature overview about the disruption brought in the finance sector by the recent technology developments. In addition to understand that technology is synonymous with innovation this paper shows examples of innovation drivers (including products and services). Finally, this paper highlights the long-term impact on social and geopolitical grounds with shifting power equilibriums, like the loosing banking monopoly of finances in favour of tech giants GAFA (Google, Amazon, Facebook, Apple) or the recent announcements of global and official cryptocurrencies, e.g. LIBRA by Facebook or CBDC (Central Banks Digital Currencies) from China government.

\section{Methodology}

Literature reviews play an important role as a foundation for all kinds of research. They are the basis for developing knowledge, producing guidelines for policy and practice, providing evidence of potential impact, and bringing forth new skills, ideas and directions for a particular field (Snyder, 2019). The method chosen in this paper is a narrative literature review approach. The idea behind this is to selectively examine literature in order to find or refute arguments for an assumption, a philosophical problem or an existing phenomenon. The approach adopted here is particularly well suited to topics that have been conceptualised differently and studied by different research groups, as is the case in FinTech. It is also useful for identifying theoretical perspectives or common problems within a particular research discipline, or for identifying components of a theoretical concept (Snyder, 2019). Possible results or discussion points are dealt with in this method and in this paper in the associated sections for argumentative reasons, so there is no extra chapter on results and discussion.

\section{A Starting Point of Fintech}

\section{Literature review}

A closer look at how and when technology began to change various aspects of the economic and financial lives shows that the Fintech industry began to revolutionize the financial sector decades before the word "Fintech" was invented. Indeed, one of the pioneering startups in digital payment services was born already in 1999 with the merger of two software companies, Cofinity and X.com (Mullan, 2016). The result of this merger was Paypal, a company that is responsible for 712 billion US dollars in transactions in 2019 alone. Even today, payments still represent the main product of FinTech activities beside lending and insurance. Furthermore, digital payment was the basis and from which new innovative solutions emerge (see figure 1). Nevertheless, FinTech is now a large sector facing a wave of specialisation, with many companies addressing different types of customers (consumers vs. businesses) or niche solutions (insurance, lending, markets, wealth and asset management, etc.). 


\section{GLOBAL FINTECH FINANCING ACTIVITY BY PRODUCTS}

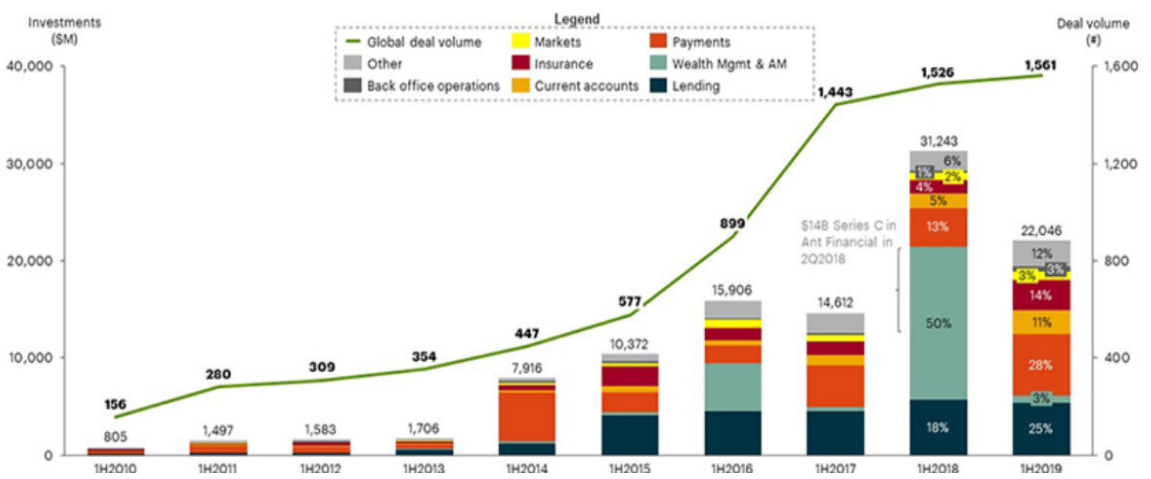

Figure 1. Global FinTech Financing - Activity by Products (Accenture, 2019)

\section{Payments}

The development of money is a process of long history, linked to the development of humanity. First, humanity learned that barter is better than self-supply, and this led to greater efficiency through the possibility of specialization. Later, it was discovered that more efficiency could be achieved by using an item as a medium of exchange to eliminate the need for the coincidence of the needs required for bartering (Wray, 2012). Money is therefore designed to facilitate exchange by acting as a "medium" or middle part of a transaction (Elwell, 2011). Throughout its development, no legal definition has been given, so that today money is defined by its functions (1. medium of exchange, 2 . unit of account and 3. store of value). Over the past 50 years, financial institutions have built payment systems that have become now partially obsolete in the wake of Fintech ruptures, such as virtual currencies or payment apps. It is stated that this new way of payment is better suited to the high expectations of a younger, digital mass that buys goods from around the world only with one touch of a phone screen (Tariq, 2020). Such "smooth" systems eliminate barriers to cross-border payments, remittances, and data transfers because they are almost instant, cheap, and secure (Tariq, 2020). In addition, entrepreneurs are designing new processes and building innovative solutions in the payments industry that enable banks and consumers to make transactions anytime, anywhere (Tariq, 2020).

\section{Cryptocurrency}

Cryptocurrency is a subset of the class of digital currency (Lee, 2015). It provides a digital asset intended to act as a medium of exchange in which individual coin owner-ship records are stored in a digital ledger or computerized database, using strong cryptography to secure transaction record entries, control the creation of additional digital coin records and verify the transfer of coin ownership (Dedi, 2018; Allison, 2015). There is usually no physical equivalent and the output is usually not provided by a central authority. Some cryptocurrencies use decentralized control as opposed to centralized digital currency and central banking systems. According to Lee, Guo and Wang (2018), the global financial crisis in 2008, in connection with a lack of confidence in the financial system, led to a significant increase in interest regarding cryptocurrency. If a cryptocurrency is coined or created prior to issuance, or is held on a central ex-change, it is generally considered centralized (Dedi, 2018). If implemented with de-centralized control, each cryptocurrency functions via a distributed ledger technology, typically a blockchain that serves as a public financial transaction database (Dedi, 2018) The first decentralized cryptocurrency is Bitcoin (Lee Guo and Wang., 2018). In June

There are central advantages of cryptocurrencies without claim of completeness:

- Protection from inflation - Only 21 million bitcoins can ever be mined, regardless of the corresponding demand for bitcoins. After all the 21 million have been mined, no new 
bitcoins will ever be produced (unless a change in protocol is made to increase supply; Faggart, 2015).

- Self-governed and managed - As all transactions are stored by "miners" on their computers and they earn fees as rewards for being accurate in their records this mechanism guarantees the integrity of information.

- Secure and private - The blockchain and others distributed ledgers used in "cryptos" are based on mathematical puzzles, which are hard to decode. This makes these currencies more secure than ordinary electronic transactions (see also Crosby, Nachiappan, Pattanayak, Verma and Kalyanaraman, 2015)

- Cost-effective mode of transaction - One of the main applications of crypto-currencies is the cross-border transfer of money. With the help of cryptocurrency, the transaction fees paid by a user is reduced to a negligible or zero amount. This is made possible by the fact that third parties, such as VISA or PayPal, no longer need to verify a transaction.

- A fast way to transfer funds - Transactions, whether international or domestic in crypto currencies, are extremely fast. The reason for this is that verification requires very little time to process, as there are very few obstacles to over-come.

\section{FinTech specialization: PropTech - WealthTech - InsurTech}

Innovative developments in the field of FinTech have led to a variety of specialisations and overlaps with other areas, such as asset management (WealthTech), insurance (InsureTech), and real estate (PropTech).

In the asset management market, (WealthTech) many companies offer so-called "ro-boadvisors". This is software that uses a mobile or web application and a reduced number of questions about the respective risk situation, individual financial goals, the level of one's own income, etc. to profile an individual ideal investment portfolio in a static or dynamic way over time. In this way, many issues of old-style advisory services are addressed and improved: 1) the machine can analyse much more data from the markets in terms of trends and financial and investment products, thus reducing the probability of "mistakes", 2) the machine can resolve any conflict of interest (usually fixed fees are paid which are in no way related to the chosen product) and 3) the partial or complete elimination of human intervention reduces costs and thus client commissions (Colangelo, 2019).

PropTech could be seen as start-up companies which use technological innovations to provide solutions to real estate problems (Aihie 2019). PropTech companies not only provide real estate services for their clients, they also enable ease of payment through collaboration with the FinTech companies that a specialised in these issue. (Aihie 2019).

According to ING (2018) PropTech be divided into three parts: Smart Real Estate, Shared Economy, and Real Estate FinTech. Smart Real Estate provide information about buildings and may directly facilitate control of building services. Technology is here used to improve the efficiency of services and meet residents' needs. Shared Economy enables the usage of real estate assets. A good example for these is co-sharing of working space or rooms and flats. Such platforms provide information's for potential users and sellers of such spaces. Real Estate FinTech provide direct products and services like access to bank loans, crowdfunding networks and analysis for monetary appreciation of property (Aihie 2019).

On the side of the insurance market (InsureTech), on-demand insurance services are also increasingly emerging, where the price of one's own insurance cover changes depending on real-time data (e.g. in the case of cars for which insurance must be paid for more or less if one's own driving style is over or under "aggressive"). Also, in the agricultural insurance sector, several companies exist that use drones and satellite monitoring as well as communication to offer different insurance rates depending on the weather and other changing environmental conditions (Accion, 2018). 


\section{The influence of GAFA on FinTech}

Google, Amazon, Facebook and Apple are making huge inroads into the financial services industry, the so-called GAFA and other BigTech can rely on at least four assets (see figure 1): many millions of customers with whom they can interact, an under-standing of their customers' motives, a huge reservoir of talented technology, marketing and product experts and massive capital reserves for investment. Surveys from mid-2017, for example by Sopra Steria Consulting, show that the majority of the industry took the threat posed by possible GAFA banks very calmly (Krakau, 2018). The reason is that the all of these companies offer payment platforms to their users, for example, such as Google Pay, Apple Pay and Amazon Pay, and Facebook users can make payments via Messenger (Langley, Leyshon 2020).

Another huge influence of GAFA on Fintech stems from the fact, that the FinTech sector highly depends on telecommunication and digital infrastructures that are largely enclosed and controlled by telecom giants and BigTech firms (O'Dwyer 2015, Sadowski 2020, Langley, Leyshon 2020). To keep a FinTech product, for example a payment app, running infrastructures like app stores, cloud servers, search engines, web analytics etc. are necessary. Most of these subjects lie in the hand of Google, Amazon, Facebook and Apple. This make GAFA very important to the political economy of FinTech as a provider of retail monetary and finance services, and as provider of the whole ecosystem platform for FinTechs (Langley, Leyshon 2020).

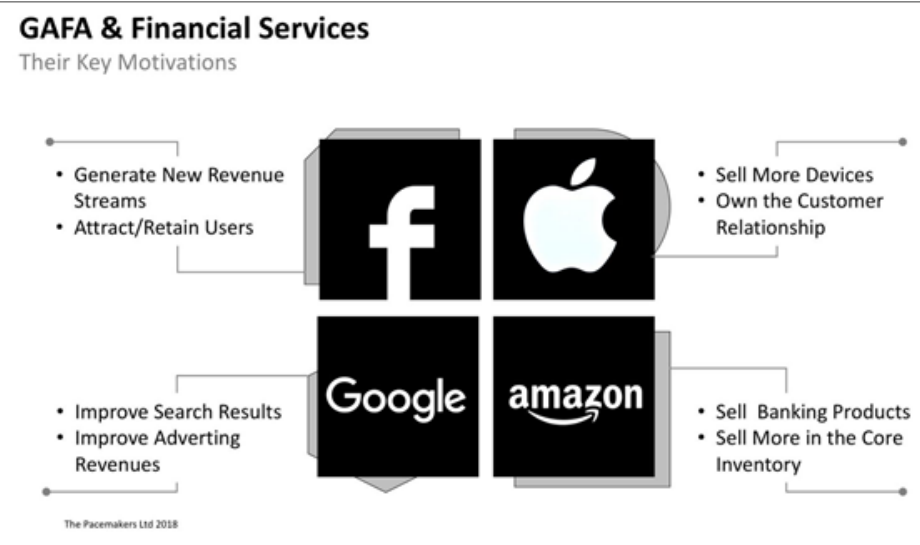

Figure 1. GAFA and financial services (Hatami, 2018)

\section{Social Impact}

\section{Results and Discussion}

In addition to the impact on economic sectors, the implications of FinTech on the social and societal structure must also be considered. FinTech has the potential to pro-mote social progress on various levels (e.g. by fostering financial literacy and inclusion; Smale, 2020; Deloitte, 2020; Pereira Arias, 2017). Likewise, technology-enabled innovations can satisfy specific consumer needs (i.e. like financial inclusion for elderly people).

For example, Grohmann, Klühs and Menkhoff (2018) showed across four indicators of financial inclusion (having a bank account, having a debit card, saving in form of a bank account and use of the debit card within the last year) that financial literacy is a significant precondition for financial inclusion. In this study, 1000 adults per country were included from each country (out of a total sample size of 143 countries). This relationship remained significant even under control for GDP and educational attainment (measured as the degree of participation in secondary and tertiary education at the country level).

Considering this beneficial effect of financial literacy on financial inclusion, it seems worthwhile to consider the potential of Fintech solutions to promote financial literacy. In this context, French, McKillop and Stewart (2020) showed in a test of four Fintech smartphone apps on Irish 
volunteers aged 16 to 65 years that their use led to significant improvements in "financial knowledge, understanding and basic skills" and "attitudes and motivations" to use online-based financial solutions. Further potentials of using Fintech solutions to promote financial literacy and inclusion should be investigated.

On the other side, there are many FinTech organisations that support social progress on a very concrete level. This includes "FinTech for Good", a global not-for-profit movement that supports smart and innovative FinTech solutions that aim, among other things, to promote financial inclusion or deal with current socially relevant questions such as climate protection (Fintech for Good, 2020). Within the Fintech sector a cur-rent trend to use new data sources to exploit new opportunities is evident. For example, Apollo Agriculture, a technology company that is based in Kenya, is helping small-scale farmers maximize their profits by using new data collection methods through satellites and machine learning (Accion, 2018). The Pilot Project "FinTech for Impact", a cooperation between ING and UNICEF, launched a multi-stage pilot pro-gram that is starting with the search, identification and investment of up to 100.000 US-Dollars in FinTech start-ups that are using FinTech solutions in the Philippines. The program is accompanied by a one-year mentorship plan to develop and monitor the social impact of these investments. The provided solutions will be as open-source outputs available for everyone (FinTech for Impact, 2020).

\section{Future of Money}

In a paper of the same name, published in 2019 by a research group of the SIX Swiss Exchange, a vision of the future, of how money should be handled and the concept of money is questioned (SIX, 2019).

A reorganisation of the scenarios designed in the report by specific, realistic, and rather shortterm trends leads to the following implication (among others, according to Fraser, 2020):

- Money, or whatever means we use to pay or store values, will be purely digital and therefore cashless.

- It is likely that different currencies will be used. In addition to dollars or euros supported by Fiat central banks, decentralized public and private cryptos will also be used, as well as other valuable digital assets (e.g., I can exchange a "share" of my Netflix subscriptions for a certain number of "digital blockbuster points", which in turn give the right to a coffee; see Fraser, 2020).

- Intelligent contract/money for use and exchange of digital vouchers, which may or may not have value depending on the external event, such as a contract of ownership for a dwelling, which only becomes real when a certain amount of "tokens" is exchanged between two counterparties.

All this, of course, brings with it an enormous change in the infrastructure, what should one do with ATMs? Can they be reused in rural areas to create "micro-local" currencies to promote recycling? Apart from that, it is tempting. There is no point in going any further with the imagination, since any technical revolution must also take account of political, legal and real economic aspects, but it is certain that sooner or later a national banknote will become a piece of an old collection.

\section{Conclusion}

The Fintech industry has the chance to revolutionize the financial sector. Nowadays FinTech is just more than Mobile Payment or Cryptocurrency. Recent developments in the field of FinTech are for example WealthTech, (InsureTech, PropTech. Beside this field new players are emerging, so called BigTech, which have new assets like technology, millions of consumers or huge capital reserves to compete within the traditional banking and finance sector. Beyond this the rise of FinTech has social impact like promoting financial literacy and inclusion and a higher acceptance of digital payments. Even on the infrastructure level FinTech has impact, e.g. what is the future of million ATM's around the world or banking offices? Future research can focus on many different aspects of FinTech. It is possible to investigate how the competition between BigTech and traditional banks will develop, 
what other forms and business areas there will be and in what form FinTech will contribute to financial inclusion. An interdisciplinary approach to measuring behavioural change and acceptance in the use of FinTech is also possible.

\section{References}

Accenture (2019): Global Fintech Investments Surged in 2018 with Investments in China Taking the Lead, Accenture Analysis Finds; UK Gains Sharply Despite Brexit Doubt, from https://newsroom.accenture.com/news/global-fintech-investments-surged-in-2018-withinvestments-in-china-taking-the-lead-accenture-analysis-finds-uk-gains-sharply-despitebrexit-doubts.htm

Accion (2018). Checking in with the startup that's revolutionizing Kenyan agriculture: Portfolio engagement: Accion Venture Lab visits Apollo Agriculture. Retrieved July 11 2020, from https://www.accion.org/fintech-startup-revolutionizing-kenyan-agriculture

Accion (2018). Three fintech trends that will reshape social impact in 2019: Discussing trends in fintech for social good at Money20/20. Retrieved July 11 2020, from https://www.accion.org/three-fintech-trends-that-will-reshape-social-impact-in-2019

Aihie, V. (2019). The PropTech Revolution: The Imperatives for Nigeria's Estate Surveying and Valuation Professionals to Catch Up or Get Left Behind. In Journal of African Real Estate Research, 4(2), 56-75.

Allison, I. (2015). Nick Szabo: If banks want benefits of blockchains they must go permissionless. Retrieved July 11 2020, from https://www.ibtimes.co.uk/nick-szabo-if-banks-want-benefitsblockchains-they-must-go-permissionless- 1518874

Colangeo, M. (2019). The Future of the Longevity Financial Industry. Retrieved July 11 2020, from https://www.linkedin.com/pulse/future-financial-longevity-industry-margaretta-colangelo

Crosby, M., Nachiappan, Y., Pattanayak, P., Verma, S., \& Kalyanaraman, V. (2015). BlockChain Technology - Beyond Bitcoin. Retrieved July 11 2020, from http://scet.berkeley.edu/wpcontent/uploads/BlockchainPaper.pdf

Dedi, D. (2018). Centralized Cryptocurrency Exchanges, Explained. Retrieved July 11 2020, from https://cointelegraph.com/explained/centralized-cryptocurrency-exchanges-explained

Deloitte (2020). FinTech and society: FinTech for the greater good? Retrieved July 11 2020, from https://www2.deloitte.com/uk/en/pages/financial-services/articles/fintech-and-society.html

Elwell, C. K. (2011). Brief History of the Gold Standard in the United States. Retrieved July 112020 , from https://fas.org/sgp/crs/misc/R41887.pdf

Faggart, E. (2015). What Happens to Bitcoin Miners When all Coins are Mined? Retrieved July 11 2020, from https://news.bitcoin.com/what-happens-bitcoin-miners-all-coins-mined/

Fintech for Good (2020). Our origins. Retrieved July 11 2020, from http://www.fintechforgood.com/index.html

Fintech For Impact (2020). The Programme. Retrieved July 11 2020, from https://www.fintechforimpact.com/programme

Fraser, I. (2020). Five new predictions for the future of money. Retrieved July 11 2020, from https://www.raconteur.net/finance/future-money-predictions

French, D., McKillop, D., \& Stewart, E. (2020). The effectiveness of smartphone apps in improving financial capability. In The European Journal of Finance, 26(4-5), 302-318. https://doi.org/10.1080/1351847X.2019.1639526

Grohmann, A., Klühs, T. \& Menkhoff, L. (2018). Does Financial Literacy Improve Financial Inclusion? Cross Country Evidence. Retrieved July 11 2020, from https://rationality-andcompetition.de/wp-content/uploads/discussion_paper/95.pdf

Hatami, A. (2018). GAFA and Banking: The Next Battleground? Retrieved from https://medium.com/@a_hatami/gafa-and-banking-the-next-battleground-1a5d14691457 
ING (2018). Technology in the Real Estate Sector. Online. Retrieved from https://think.ing.com/uploads/reports/ING_EBZ_PropTechTechnlogy_in_the_real_estate_sector-June_2018_tcm162-148619.pdf

Krakau, U. (2018). GAFA: Wenn Giganten den Bankenmarkt entdecken. Retrieved July 112020 , from https://www.springerprofessional.de/bankstrategie/e-commerce/gafa--wenn-gigantenin-den-bankenmarkt-einstei Retrieved from gen/15761242

Langley, P. \& Leyshon, A. (2020). The Platform Political Economy of FinTech: Reintermediation, Consolidation and Capitalisation. In New Political Economy, https://doi.org/10.1080/13563467.2020.1766432

Lee, D.K.C. (2015). Handbook of Digital Currency. San Diego: Elsevier.

Lee, D.K.C., Guo, L., \& Wang, Y. (2018). Cryptocurrency: A new investment opportunity? In. Journal of Alternative Investments, 20(3), 16-40.

Leong, K. (2018). FinTech (Financial Technology): What is It and How to Use Technologies to Create Business Value in Fintech Way? In International Journal of Innovation, Management and Technology, 74-78. https://doi.org/10.18178/ijimt.2018.9.2.791

Mullan, P. C. (2016). A History of Digital Currency in the United States: New Technology in an Unregulated Market. Palgrave Advances in the Economics of Innovation and Technology. New York: Palgrave Macmillan US.

O'Dwyer, R. (2015). Money talks: The enclosure of mobile payments. In G. Lovink, N. Tkacz, and P. De Vries, ed. Moneylab reader: an intervention in digital economy. Amsterdam: Institute of Network Cultures, 230-44.

Pereira Arias, M. (2017). Financial Technology and Social Impact: The New Social Fintech Sector. Retrieved July 11 2020, from https://socialfintech.org/financial-technology-and-socialimpact-the-new-social-fintech-sector/

Sadowski, J., 2020. The internet of landlords: digital platforms and new mechanisms of rentier capitalism. Antipode, 52 (2), 562-80.

Schueffel, P. (2017). Taming the Beast: A Scientific Definition of Fintech. In Journal of Innovation Management, 4(4), 32-54. https://doi.org/10.24840/2183-0606_004.004_0004

Six (2019). Future of Money. Retrieved July 11 2020, from https://www.sixgroup.com/dam/download/company/report/whitepapers/six-whitepaper-future-of-moneyfull-version-en.pdf

Smale, N. (2020). FinTech for social impact. Retrieved July 11 2020, from https://theshift.media/features/fintech-for-impact

Snyder, H. (2019): Literature review as a research methodology: An overview and guidelines. In Journal of Business Research, 104, 333-339. https://doi.org/10.1016/j.jbusres.2019.07.039

Tariq, I. (2020). How Fintech Startups Are Disrupting the Payments Industry. Retrieved July 11 2020, from https://www.entrepreneur.com/article/346185

Wray, L. R. (2012). Introduction to an Alternative History of Money. Retrieved July 112020 , Working Paper No. 717, from http://www.levyinstitute.org/pubs/wp_717.pdf 